Conventional Treat-to-Target Strategies on Disease Activity Remission and Radiographic Progression in Rheumatoid Arthritis: The IMAGINE-RA Randomized Clinical TrialEffect of MRI vs Conventional Treat-to-Target Strategies on Disease Activity Remission in RAEffect of MRI vs Conventional Treat-to-Target Strategies on Disease Activity Remission in RA. JAMA. 2019 Feb 5;321(5):461-72

[4] Mangnus L, van Steenbergen HW, Reijnierse M, van der Helm-van Mil AHM. Magnetic Resonance Imaging-Detected Features of Inflammation and Erosions in Symptom-Free Persons From the General Population. Arthritis \& Rheumatology. 2016;68(11):2593-602

Disclosure of Interests: None declared

DOI: 10.1136/annrheumdis-2019-eular.8562

FRIDAY, 14 JUNE 2019

15:30:00 - 17:00:00

The multiple rheumatological faces of PsA (or PsA
is more than just poly-arthritis? - Consequences
for management in daily practice)

SP0142 CASE 1 PRESENTER: A PATIENT WITH PERSISTING MONO/OLIGO-ARTHRITIS (EITHER AT START OR REMAINING AFTER TREATMENT OF POLY-ARTICULAR DISEASE)

William Tillett. Royal National Hospital for Rheumatic Diseases, Rheumatology, Bath, United Kingdom

Background: The varied clinical phenotypes of psoriatic arthritis present treatment challenges in clinical practice. The dominant phenotype represented in clinical trials is polyarthritis with little representation of oligoarticular or monoarticular disease.

Objectives: To review the phenotypes of psoriatic disease and treatment of resistant oligo/monoarthritis in the context of a clinical case.

Methods: Clinical case history

Conclusion: The clinical phenotype of articular disease in psoriatic arthritis can evolve over time. There is limited data to inform the treatment of resistant oligo/ monoarthritis

Disclosure of Interests: William Tillett Grant/research support from: AbbVie, Celgene, and Lilly, Consultant for: AbbVie, Celgene, Lilly, Novartis, and Pfizer, Speakers bureau: Abbvie, Celgene, Lilly, Janssen, Novartis, UCB, and Pfizer DOI: 10.1136/annrheumdis-2019-eular.8602

\section{SP0143 CASE 1 DISCUSSANT: HOW IS TACKLING OLIGO- ARTICULAR DISEASE DIFFERENT FROM POLYARTHRITIS? CAN WE USE TRIAL RESULTS FROM POLY-ARTICULAR PSA IN A PATIENT WITH MONO/ OLIGO-ARTHRITIS?}

Laura C Coates. University of Oxford, Nuffield Department of Orthopaedics, Rheumatology and Musculoskeletal Sciences, Oxford, United Kingdom

Background: Oligoarthritis is a well recognised phenotype in psoriatic arthritis (PsA) where less than 5 joints are involved with active arthritis. In cohort studies, the proportion of patients presenting with mono/oligoarthritis varies from $20-70 \%$ depending on the timeframe studied and duration of disease. However most studies of therapeutic agents in PsA have focused on polyarticular disease. Although the majority of studies accept a minimum of 3 active joints for inclusion, the average tender and swollen joint counts are usually over 10 at baseline.

Objectives: To review data supporting treatment of psoriatic mono/oligoarthritis including comparisons of response rates in therapeutic trials in PsA and the differential performance of outcome measures in this subtypes of disease.

Results: When considering the applicability of RCT data to mono/oligoarthritis in PsA it is important to address the populations included in these studies. Nearly all large therapeutic studies exclude monoarthritis, and while some oligoarthritis patients are eligible for inclusion in most RCTs, the demographics of the population included suggest that this is a minority. Unfortunately most clinical trials have not reported the efficacy results separately for oligoarthritis and polyarthritis patients. The other key consideration is that the outcome measures used in the majority of trials are developed and validated on patients with polyarticular PsA. Thus assessing effectiveness of therapies may be limited in the oligoarthritis population as the response measures are less sensitive to change.

Conclusion: Although data from polyarticular RCT populations is often used to choose therapies in oligoarticular PsA, there is a real paucity of data to ensure that we are treating these patients optimally. Future research is needed to address the variable prognosis seen in mono/oligoarticular PsA, to ensure that appropriate outcome measures are used to test different therapies and to provide clear evidence on the efficacy of drugs in this important subtype of disease.

Disclosure of Interests: Laura C Coates Grant/research support from: AbbVie Celgene, Lilly, Novartis and Pfizer, Consultant for: AbbVie, Amgen, BMS, Celgene, Galapagos, Gilead Sciences Inc., Janssen, Lilly, Novartis, Pfizer, Prothena Corp and UCB

DOI: 10.1136/annrheumdis-2019-eular.8448

\section{SP0144 CASE 2: SOLITARY ENTHESITIS AS A THERAPEUTIC CHALLENGE}

Philippe Carron. Ghent University Hospital, Rheumatology, Gent, Belgium

The enthesis is a site crucial for mobility of the musculoskeletal system yet it is also commonly a target of inflammation, especially in spondyloarthritis. Because the enthesis is prone to high biomechanical forces, it has been hypothesized that biomechanical forces may be implicated in the onset of the enthesitis and spondyloarthritis in general. However, treatment recommendations involve exercise therapy which at first glance appears to pose a paradox. Using a case, we will discuss the current knowledge on enthesitis, the link with mechanical stress and the implications thereof in diagnosis and management of spondyloarthritis.

Disclosure of Interests: None declared

DOI: 10.1136/annrheumdis-2019-eular.8442

\section{SP0145 \\ CASE 2 DISCUSSANT: ENTHESITIS AND THE CONCEPT OF MECHANICAL STRESS}

Dirk Elewaut. Ghent University Hospital, Rheumatology, Ghent, Belgium Philippe Carron and Dirk Elewaut, VIB Inflammation Research Institute, Ghent University and Department of Rheumatology, Ghent University Hospital

The enthesis is a site crucial for mobility of the musculoskeletal system yet it is also commonly a target of inflammation, especially in spondyloarthritis. Because the enthesis is prone to high biomechanical forces, it has been hypothesized that biomechanical forces may be implicated in the onset of the enthesitis and spondyloarthritis in general. However, treatment recommendations involve exercise therapy which at first glance appears to pose a paradox. Using a case, we will discuss the current knowledge on enthesitis, the link with mechanical stress and the implications thereof in diagnosis and management of spondyloarthritis

Disclosure of Interests: None declared

DOI: 10.1136/annrheumdis-2019-eular.8468

FRIDAY, 14 JUNE 2019

15:30:00 - 17:00:00

\section{Cannabis for arthritis: hype or hope?}

\section{SP0146 BENEFITS OF CANNABIS TO YOUR JOINTS: HYPE OR HOPE?}

Serge Perrot. France, France

Cannabis-based medicines have been approved for pain management in a number of countries. However, there are uncertainties and controversies about their role and the appropriate use of these medicines for the management of chronic pain, particularly in musculoskeletal conditions. These ancient drugs are now being rediscovered and considered as modern analgesic approaches in the context of cannabis legalization in more and more countries. The fight for cannabis legalization is frequently confused with the search for new analgesics in a medical context. Furthermore, there is a confusion between herbal cannabis, medical cannabis and cannabinoids. Therefore, it is important to differentiate products and 